\title{
What Affects the Production Technology of Labor-Intensive Agricultural Industries in the Context of Labor Aging? An Empirical Study Based on the Garlic Production in Lanling
}

\author{
Fujia Sui, Yinsheng Yang * and Shizhen Zhao \\ College of Biological and Agricultural Engineering, Jilin University, 5988 Renmin Street, \\ Changchun 130022, China; suifj20@mails.jlu.edu.cn (F.S.); zhaosz20@163.com (S.Z.) \\ * Correspondence: yys@jlu.edu.cn
}

Citation: Sui, F.; Yang, Y.; Zhao, S. What Affects the Production Technology of Labor-Intensive Agricultural Industries in the Context of Labor Aging? An Empirical Study Based on the Garlic Production in Lanling. Sustainability 2022, 14, 48. https://doi.org/10.3390/su14010048

Academic Editor: Piotr Prus

Received: 25 November 2021 Accepted: 17 December 2021 Published: 21 December 2021

Publisher's Note: MDPI stays neutral with regard to jurisdictional claims in published maps and institutional affiliations.

Copyright: (C) 2021 by the authors. Licensee MDPI, Basel, Switzerland. This article is an open access article distributed under the terms and conditions of the Creative Commons Attribution (CC BY) license (https:// creativecommons.org/licenses/by/ $4.0 /)$.

\begin{abstract}
While the aging of agricultural labor force and its impact on agricultural production have been attracting extensive attention, little is known about the relationship between aging of agricultural labor force and technical efficiency in the garlic production. Based on the survey data of garlic growers in Lanling County, Shandong Province, the Data envelopment analysis (DEA) model is used to measure the production technical efficiency of garlic growers in 84 villages in Lanling County, Shandong Province, with the aging of the labor force. The distribution characteristics and changing trends of garlic production technology efficiency are analyzed in terms of family characteristics and garlic planting characteristics, and regression analysis is performed on the differences of the results. The study found the following: (1) Garlic growers in Lanling County, Shandong Province, accounted for a high proportion of laborers over 60 years old, and their physical health status was weaker than that of young laborers, which reduced the technical efficiency of garlic planting and production. (2) The number of garlic varieties grown by garlic growers and the number of garlic planted in acres have a significant negative impact on the technical efficiency of garlic planting by farmers. (3) There is a significant positive correlation between the annual household income of farmers and the production technology efficiency of garlic growers; when the number of garlic training is not more than three times, it has a positive impact on the production technology efficiency of garlic planting by farmers, and more than three times are related to garlic production technology. The efficiency is negatively correlated.
\end{abstract}

Keywords: garlic planting; aging labor force; DEA; Tobit; Lanling County

\section{Introduction}

Since the 1980s, with the rapid economic development, the proportion of China's aging population has been increasing [1], and the proportion of the population engaged in primary industry has declined [2], which leads to the aggravation of the aging degree of the labor force [3]. The aging of the agricultural labor force is an important part of the labor aging process. This problem is widespread in countries and regions such as China, the United States, Japan, Europe, Southeast Asia, and Oceania. It is a worldwide problem. However, due to the differential development of labor endowment in various countries, it has attracted the attention of many agricultural economists. It is worth noting that although the aging of agricultural labor force in China appears later than that in high-level developed countries such as Europe and the United States, it has become an important issue or problem hindering rural development due to the coupling of agricultural fundamentals and agricultural development levels $[3,4]$. As an important indicator reflecting the ability to effectively use resources under existing production conditions, production technical efficiency can objectively evaluate the current development level of a specific industry and deeply reflects the impact of an aging labor force on some key links of the industry. Agriculture is one of the important industries of the national economy, and the level of labor supply is one of the important factors to ensure the sustainable development of agricultural 
planting production. Scientific and effective evaluations of the impact of labor aging on the efficiency of production technology can be used to accurately implement policies and promote the sustainable development of agricultural production.

In China, different from the traditional field crop agriculture led by rice and wheat, the high value-added, labor-intensive industry of vegetables and fruits represented by garlic planting is of great significance in absorbing the agricultural labor force and increasing foreign exchange income. The garlic planting process has high requirements for labor force and the physical fitness of the labor force. Under the background of the accelerating aging of agricultural labor force in China, its production behavior is facing the problem of labor endowment changes caused by aging of the workforce/aging of labor force. The change in labor endowment will affect the technical efficiency of garlic production, which has a unique influence mechanism. Studying the impact of the aging of labor force on the production technical efficiency of the garlic planting industry can not only provide a theoretical basis for the development of the garlic planting industry but also provide a corresponding theoretical model for the research on the production technical efficiency of similar high value-added, labor-intensive industries and also realize the sustainable production of related crops under the background of aging labor.

China is the world's largest garlic producer and exporter, accounting for $59.56 \%$ of the world's garlic harvest area and output. Lanling County, Shandong Province, is known as the "Hometown of Garlic in China". As shown in Table 1, the garlic planting area in 2020 is $23,533.33 \mathrm{ha}$, an increase of $6.97 \%$ year-on-year, accounting for $30.6 \%$ of the economic crop planting area in Lanling County. At the same time, the garlic output value of Lanling County accounts for $19.92 \%$ of the total agricultural output value of Lanling County (including grain, cash crops, etc.). Therefore, garlic is one of the main sources of income for farmers, and it is of practical significance to improve its production efficiency so that farmers can obtain more income.

Table 1. Basic information about Lanling garlic.

\begin{tabular}{cccc}
\hline Year & $\begin{array}{c}\text { Garlic Planting Area } \\
\text { (ha) }\end{array}$ & $\begin{array}{c}\text { Garlic Production } \\
\text { (hundred million kg) }\end{array}$ & $\begin{array}{c}\text { Total Output Value of Garlic } \\
\text { (hundred million yuan) }\end{array}$ \\
\hline 2018 & $21,333.33$ & 3.26 & 17.43 \\
2019 & 22,000 & 3.25 & 17.66 \\
2020 & $23,533.33$ & 6.947 & 7.16 \\
(ha)
\end{tabular}

Data sources: Lanling County Statistical Yearbook.

This study aims to investigate the impact of the aging agricultural labor force on the technical efficiency of garlic production in the one of the main garlic production areas, Lanling County, Shandong Province, China. The DEA-Tobit method was used to identify the influencing factors of the aging labor force on the production technical efficiency of garlic growers. The above method puts forward suggestions on optimizing the production behavior of garlic growers and coping with the impact of the aging labor force on garlic planting production.

The technical contributions of the article to existing research are as follows:

The article analyzes and studies the impact of the aging agricultural labor force on the efficiency of garlic production technology, seeks for ways to improve the efficiency of garlic planting production technology under the condition of resource constraints, and makes an important supplement to the research on the production technical efficiency of garlic planting industry.

By studying the efficiency of garlic production technology and analyzing and researching the influence of the aging agricultural labor force on producer behavior in labor-intensive industries, this article realizes the cause analysis of producer behavior in labor-intensive industries and enriches the research theory of aging labor forces in labor-intensive crops.

Based on the two-stage method, the article integrates the DEA method and the Tobit method, realizes the regression of continuous variables and classified variables at the same 
time, and accurately and efficiently analyzes the influencing factors, which can be widely applied to the quantitative problem of agricultural total factor input.

The following part of this research consists of five parts. The second section first reviews the literature on the aging of agricultural labor force and the efficiency of production technology, and in the third section, it presents a theoretical analysis of the impact of the aging of agricultural labor force on the efficiency of garlic production technology, then puts forward a research hypothesis. The fourth section is the calculation of the production technical efficiency of garlic growers, the construction of the regression model, and data source analysis, and in the fifth section, it calculates the results of technical efficiency and analyzes the influencing factors of the aging agricultural labor force on technical efficiency and describes the data sources. The sixth section is the research results and policy implications of this article.

\section{Literature Review}

\subsection{The Research on the Impact of Aging of Agricultural Labor Force}

In view of the above background, the aging of agricultural labor force has aroused the attention of many scholars. It found that farming is still the main source of agricultural income for elderly workers over 60 years old in China's rural areas, and agricultural production is still dominated by elderly labor, that is, elderly laborers still make a greater contribution to agricultural production [4]. Hu Xuezhi (2012) and others found that the phenomenon of outsourcing agricultural machinery operations mostly exists in the current agricultural production, and then it is concluded that the impact of the elderly labor on agricultural production is not significant [5]. In addition, in further research, Hu Xuezhi (2013) and other studies found that the aging of the agricultural labor force had no significant impact on the input of wheat and cotton [6]. However, scholars are divided over the research conclusions on the impact of aging of agricultural labor force on agricultural output. The research of Lin Benxi and Deng Hengshan (2012) believes that the aging agricultural labor force has a significant impact on labor input in agricultural production. Ref. [7] Thiede, Brian C (2017), and others made use of the relevant population and labor force data of the United States to analyze and conclude that most of the rural areas and communities in the United States have a high degree of aging, which affects social production [8]. Peter Smailes (2014) and others used the relative aging index to compare the differences between the aging of rural population and urban aging. Studies show that the degree of aging in rural areas is more serious, the degree of aging in agriculture-based areas is much higher than that in urban areas, and the level of agricultural production is worrying [9]. Toossi M. et al. (2002) analyzed and evaluated the labor supply in the United States, and it is concluded that compared with 1950, in this situation, the future American agricultural labor force will always show the characteristics of aging, decentralization, and feminization, thereby affecting production [10]. When Despotovie, Aleksandra (2015), and others studied the relationship between agricultural aging and agricultural development in Montenegro, they found that the aging of the rural labor force and lower education levels are important factors affecting agricultural development and therefore directly affect agricultural production output [11]. Lindh, Thomas, and Malmberg, Bo (1999) believe that the population age structure of a country or region determines the situation and demand changes of human resources. At the same time, the economic growth rate depends on these two factors. Therefore, the authors used 40 years of OECD data to analyze the relationship between population age and per capita GDP. The results showed that the population aged 65 and over has only a negative impact on it [12].

The existing research shows that the research on the impact of aging of the rural population or aging of agricultural labor force on agricultural production is mainly focused on food crops that can be planted with a high degree of mechanization or non-designated cash crops. Scholars have not been paying much attention to agricultural labor-intensive industries. Therefore, this article further supplements the existing theoretical research on 
the aging of agricultural labor force from the perspective of the research object by focusing on the aging of agricultural labor in the garlic planting industry.

\subsection{Quantitative Research on Agricultural Production Technical Efficiency}

Production technical efficiency is an important indicator reflecting the ability to effectively use resources under existing production conditions. It can deeply analyze the causes of aging. Many scholars have conducted a series of studies on the impact of agricultural labor aging on production technical efficiency.

The Research of Lin Benxi and Deng Hengshan (2012) shows that because agricultural production is a repetitive activity with little impact on technical know-how, age has no significant effect on the utilization efficiency of cultivated land, and it is concluded that the aging of agricultural labor force has no significant impact on the input of agricultural production factors [7]. Guo Xiaoming (2015) and others believe that the output elasticity of labor input will change according to the input of chemical fertilizers, pesticides, and other biotechnology. The existence of traditional labor cultivation agriculture is not completely negative. Through analysis, the author concludes that the output of labor input is higher than that of agriculture. Income from mechanical input and traditional artificial planting has a low negative impact on agricultural production, and the traditional artificial planting has a low negative impact on agricultural production [13]. Liu Chao (2018) and others believe that the number of laborers, the consumption and cost of chemical fertilizers per unit area, the use and operating costs of agricultural machinery, and the time trend of technological progress have a significant promoting effect on the yield per unit area of corn, while the age of the labor force is not related to the efficiency of production technology [14] Pakapon Saiyut (2018) conducted a stochastic frontier analysis on the panel data of 76 provincial agricultural production in Thailand over 4 years and estimated that the age of the agricultural labor force had no negative impact on technical efficiency [15].

However, Abdulai (2001) believed that the loss of agricultural production technical efficiency was mainly due to the transfer of the agricultural labor force and began to participate in non-agricultural activities, resulting in insufficient labor supply [16]. Using the survey data of 745 apple-growing farmers in Shaanxi and Gansu provinces of China, Qiao et al. believed that there is an inverted U-shaped curve between the age of farmers and the efficiency of apple production technology. The age turning point is 50-54 years old, after which the planting efficiency begins to decrease [17]. Harold O. Fried and Loren W. Tauer (2016) used the age data of the agricultural census from 50 states in the United States and used the DEA model to calculate the technical efficiency of rural labor in different age groups. The results showed that the productivity of the 35-44 age group was 3 percent higher than the productivity of younger laborers under the age of 25 , but the productivity of laborers aged 65 and over is the lowest, $10 \%$ lower than that of young laborers aged 25 . Farmers' age and non-agricultural income have a positive relationship with inefficiency [18]. Bashir and MK's research shows that in potato production, the age of the growers has a negative impact on the efficiency of production technology [19].

In summary, when studying the efficiency of agricultural production technology, scholars seldom study the production technology efficiency of labor-intensive cash crops, especially the research on the production technical efficiency of garlic growers on the aging of the agricultural labor force. This article analyzes the factors that affect the efficiency of its production technology and puts forward suggestions for garlic growers to increase the production capacity of garlic. The research results are a beneficial supplement to the theory of production technical efficiency.

\subsection{Production Technical Efficiency Research Tool}

Data envelopment analysis (DEA) and stochastic frontier analysis (SFA) models are the main research tools used to calculate production technical efficiency. DEA is a nonparametric method and does not set specific function form but is a model to find relative efficiency value; the stochastic frontier analysis model is a way to calculate the absolute 
efficiency value, which can only estimate the best efficiency but cannot obtain the average efficiency. In this paper, the DEA model is chosen to obtain the relative efficiency value through the cross-sectional data, which is the same as the model used in other research, and the Tobit model is combined to obtain the influencing factors. Hakim, R's research aims to use data envelopment analysis (DEA) to measure the technical efficiency of rice and its determinants. The results show that the efficiency of rice planting technology in East Java is very low [20]. From an energy perspective, Anser calculates the overall technical efficiency of China's agricultural sector through the DEA model and the total factor framework [21]. Monchuk et al. used DEA to implement a truncated regression model to obtain an estimated score of agricultural production inefficiency in China [22]. Indian scholars Ray and Ghose also used the same DEA method to record technical efficiency [23]. Pan et al. used DEA to calculate the technical efficiency of 18 regions in Botswana from 1981 to 1996 [24]. The output of rice (0.60) and wheat (1.00) recorded by Aslam and MS through the CCR method can be regarded as the highest productivity to encourage high-yield and appropriate planting methods in specific areas [25]. Sun Zhilu and others used the Tobit model to analyze the influencing factors of TEFU and found that TEFU has significant differences in different varieties and production provinces in rice production in my country [26]. Sapkota, $\mathrm{M}$ used the Tobit model to determine the factors affecting corn planting when studying the factors related to the efficiency of corn seed production technology in the central mountainous area of Nepal [27]. Mezgebo, GK used a Tobit model to determine the influencing factors of sesame production [28]. Angon, E estimated the TE score through the input data encirclement analysis (DEA) model, and in the second stage, Tobit regression determined the determinants of the inefficiency of the evaluation technique [29].

Literature studies have shown that DEA is suitable for multi-input and multi-output production mode efficiency evaluations, which can analyze and measure multiple inputs and outputs, and the DEA-Tobit model using a two-stage method can not only carry out regression on continuous variables but also carry out regression on classified type variables, which is relatively accurate for the analysis of influencing factors, so it is suitable for the study of quantitative issues of agricultural total factor input.

\section{Theoretical Analysis}

Chayanov pointed out that farmers are the most basic activity unit in agricultural production with independent decision-making capabilities. The farmers' choice of production factor input allocation will be affected by differences in labor endowments, and the total output will also change due to the change of production factor inputs [30]. The increase in crop yields mainly depends on the input of factors such as fertilizers, pesticides, and irrigation, as well as the adoption of good technologies. In modern agriculture, the technology adoption and technical efficiency play a vital role in promoting a growth of agricultural output [31,32]. In other words, given certain factor inputs, fully effective utilization of the technology can produce the highest output. Therefore, technical efficiency is usually used to measure whether the best available technology is adopted and effectively utilized in agricultural production [33]. When using DEA to analyze the technical efficiency of garlic growers, the initial efficiency is reflected in the gap between the production state of a certain decision-making unit and the best production state, thereby showing the relationship between input and output to obtain the best yields and unit input value and then promote farmers' planting efficiency. Generally speaking, if the technical efficiency is equal to 1 , then the best available technology is adopted and effectively utilized. Otherwise, some technical efficiency may be lost. Much of the literature focuses on the determinants of agricultural technical efficiency [32-35], and more and more research focuses on the aging of the agricultural labor force [3,17]. The impact of the aging agricultural labor force on the technical efficiency of garlic production may depend on empirical and physical effects. In the garlic production process, the aging of the agricultural labor force leads to insufficient household labor supply, and labor is restricted by quantity and quality. At the same time, aging affects household income and makes garlic planting and production have potential 
capital supply constraints. The basic production factors of garlic production are land, labor, and capital. Within a certain range, these three factors have a relationship of substitution and complementarity. The labor difference caused by aging makes garlic growers allocate land, labor, and capital resources rationally, and then shows the difference in the labor force the input of production factors.

As shown in Figure 1, the economic explanation is based on Low's farmer model. Without adding other factors of production input, assuming that garlic output in the short term increases in proportion to the increase with labor input, OL represents the labor input of garlic growers, from left to right represents an increase in input, and OR represents the output of growers. From bottom to top, it means the output of garlic increases proportionally with the increase in labor input. $\mathrm{OL}_{\mathrm{o}}$ and $\mathrm{OL}_{n}$ are assumed to be the labor productivity of elderly and younger and middle-aged growers, respectively. Due to the differences in labor force between different ages, the productivity of older growers is generally lower than that of young and middle-aged growers. Therefore, under the labor input of point L1, the value of point OA is greater than that of OB [36]. In this case, if elderly growers want to achieve the same output as younger and middle-aged growers, they must reach a new labor productivity $\mathrm{OL}_{\mathrm{o}}^{\prime}$, which can only be achieved by increasing labor input from $L_{1}$ to $L_{2}$, or through other channels such as hiring workers or adding agricultural machinery to make up for the gap in labor input from $\mathrm{L}_{1}$ to $\mathrm{L}_{2}$. However, any factor substitution will result in a change in the input status of the growers' production factor, which is manifested as changes in the type and quantity of the input of the production factor. Accordingly, by comparing the land, labor, and capital input of different types of growers, the influence and performance of the aging of the agricultural labor force on the land, labor, and capital input of garlic growers are analyzed.

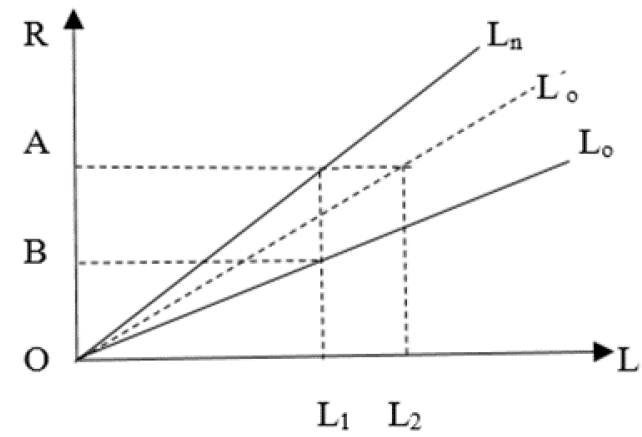

Figure 1. The labor productivity difference of garlic growers.

With the increase in the age of the agricultural labor force, the land input, labor input, and capital input of farm households all show an inverted U-shaped trend of rising first and then falling. There are significant differences in factor input among farm households of different ages. The sown area of crops of the elderly farmers is smaller, but their labor input has a smaller decline compared with the young and middle-aged labor force. They tend to extend the working time and increase the labor input to replace capital input; in the agricultural production of the young and middle-aged farmers, the agricultural capital input is all the largest, while the young households are physically strong but the production scale labor input and capital input is the smallest, and they are more willing to go out to work for non-agricultural income.

The aging of agricultural labor forces restricts the supply of labor and capital. The older the agricultural labor force, the physical aging and the capital squeeze effect are particularly obvious after the middle-aged, leading to varying degrees of decline in inputs of production factors. At the same time, the decrease in household income reduces capital input and thus reduces the efficiency of production technology.

In this study, changes in the scale of garlic growers will help to adopt and use better technologies more effectively [37]. If the change in the planting scale of garlic growers is 
caused by the same proportion of the increase or decrease in inputs of all production factors, there are three corresponding changes in income: If the proportion of increase in income is greater than the proportion of increase in input, it means that garlic growers are in the stage of increasing returns to scale (as shown by curve A in Figure 2). Expanding the scale of planting can be achieved through the research of advanced technology and the promotion of small and medium-sized agricultural machinery equipment, thereby expanding the degree of mechanization of garlic planting, realizing large-scale specialized operations, improving the technical efficiency of garlic production, and reducing production costs. The small-scale garlic growers limit the use of advanced technology and agricultural machinery, if the increase in income equals the increase in input, it means that garlic growers are producing at the optimal scale, and the return to scale remains constant (curve B). If the increase in output is less than the increase in the penetration of production factors, then garlic growers are in a stage of diminishing returns to scale (curve $C$ ), indicating that the scale of production is too large, which is not conducive to fine management, and there are too many input factors of production. Therefore, the efficiency of resource allocation can be improved by optimizing the combination of production factors. Generally, the initial stage of garlic growers' scale expansion is to increase the return on scale, then experience a constant return on scale, and finally reach the stage of return on scale. The optimal scale is not necessarily the largest scale, and the returns of the three input-output scales are not independent of each other but are in the three stages in the entire production process.

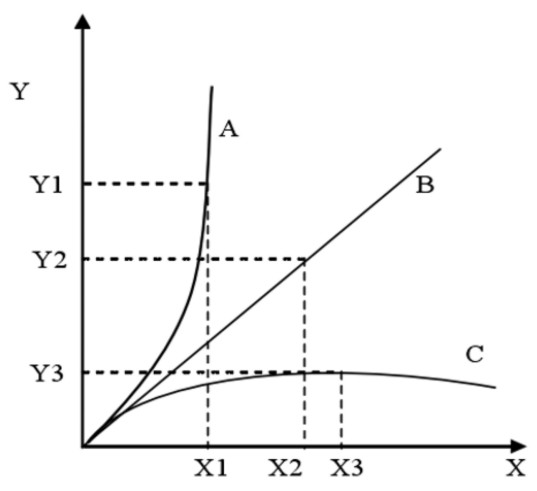

Figure 2. Diagram of returns to scale.

\section{Methods and Data}

\subsection{Data Envelopment Analysis and Econometric Model}

Using a data envelopment analysis and econometric model, this study aims to study the impact of the aging of agricultural labor force on the technical efficiency of garlic production in Lanling County, Shandong Province, China, in which the estimation of technical efficiency is very important. In this part, we first introduce the method of calculating technical efficiency and then build a model to test the impact of the aging of the agricultural labor force on technical efficiency. Generally speaking, there are two basic methods for estimating technical efficiency: (a) non-parametric methods, such as data envelopment analysis (DEA), and (b) parametric methods, such as stochastic frontier analysis (SFA) [38,39]. In the previous literature on efficiency analysis, both methods have been widely adopted. In short, DEA can calculate technical efficiency in a linear programming way, while SFA can calculate technical efficiency based on the estimation of the stochastic frontier production function [13]. As a non-parametric statistical method, the DEA model takes the concept of relative efficiency as the basis and uses input-output data to estimate the gap between the decision-making unit and the frontier of effective production. It can also measure the same type of multiple-input and estimate if the multiple-output decision-making units are effective. The DEA model used in this paper is a variable-scale model, which is used to analyze the technical efficiency of agricultural production to obtain the relative comprehensive technical efficiency, pure technical efficiency, and scale efficiency 
values and analyze the effectiveness of the selected decision-making unit on this basis. The DEA model usually has two forms, the first is the CCR model with constant return to scale, and the second is the BCC model with variable return to scale [28,29].

In this study, garlic production is affected by three types of labor, land, and capital inputs. The premise of using the CCR model is that the return to scale of production remains constant, but the actual production situation is different from the assumption, so the BCC model is selected. Under the condition of variable returns to scale, pure technical efficiency is the same as comprehensive efficiency. The measurement standard is the distance between the production decision-making unit and the production frontier. However, unlike comprehensive efficiency, pure technical efficiency is affected by factors such as management and technology production efficiency. Scale efficiency (SE) refers to the distance between the frontier of production when the return to scale of the decision-making unit is constant and the frontier of production when the return to scale is variable. Therefore, both comprehensive technical efficiency and pure technical efficiency are related to scale efficiency, and the efficiency value is the ratio of comprehensive technical efficiency and pure technical efficiency. Scale efficiency measures the degree of influence of production scale on technical efficiency.

In imperfectly competitive markets, when the decision-making unit is generally unable to operate at the optimal scale, the variable return to scale BCC model can be used. According to the status quo of garlic planting in Lanling County, this paper adopts a VRS model. Only the input of production factors can be controlled and adjusted by farmers during the planting process, and natural output cannot be controlled manually. Therefore, this paper adopts the BCC input-oriented model to measure the sample of farmers. The index value range is $(0,1)$ (left open and right closed area). The larger the value is, the higher the efficiency is.

$$
\begin{gathered}
\max E_{k}=\frac{\sum_{r=1}^{s} u_{r} y_{r j}-u_{j}}{\sum_{i=1}^{n} v_{i} x_{i j}} \\
\text { s.t. } \\
\sum_{i=1}^{n} v_{i} x_{i j}=1 \\
\sum_{r=1}^{s} u_{r} y_{r j}-\sum_{i=1}^{n} v_{i} x_{i j}-u_{j} \leq 0 \\
u_{r}, v_{i} \geq 0(r, j=1,2, \ldots \ldots, s, n)
\end{gathered}
$$

In Equation (1), $E_{k}$ is the production efficiency of the $k$-th farmer; $x_{i j}$ is the $i$-th input value of the $j$-th farmer. This article mainly considers three types of inputs: $y_{r j}$ is the $r$-th output value of the $j$-th farmer, and this paper only considers one output; $u_{r}$ and $v_{i}$ are the weights of output and input, respectively. Specifically, one output is garlic output income; the three inputs are land input, capital input, and labor input.

We can further develop an econometric model to estimate the relationship between the age of the agricultural labor force and other factors and technical efficiency. This study uses a two-step method, in which Equation (1) obtains the value of production technical efficiency, and then as the second step, a separate regression model for estimating the determinants of technical efficiency. The Tobit model is a popularization of Probit regression by James Tobin, a famous American economist, and it is an econometric model with restricted explanatory variables. The efficiency value of garlic production technology obtained by data envelopment analysis ranges from 0 to 1, with discrete data with truncated characteristics. If the least squares method is selected for regression analysis, there will be situations in which the data cannot be presented completely, so the estimated value will have a large deviation. Therefore, choosing the Tobit model based on the maximum likelihood estimation method for regression analysis can better process the efficiency data, so as to perform regression analysis on the factors that affect the efficiency of production technology and obtain the degree of influence of each factor on the efficiency of garlic 
planting production technology. In 1998, Coelli proposed a two-stage efficiency analysis method. First, the data envelopment analysis method was used to measure the technical efficiency of garlic production, and then the efficiency value obtained was used as the explained variable, and the Tobit model was used to perform regression with Stata13.1 software to analyze the factors affecting technical efficiency of garlic production. The basic form of the Tobit model is:

$$
\begin{aligned}
& y^{*}=\beta x_{i}+\varepsilon_{i} \\
& y_{i}=0, y_{i}^{*}<0 \\
& y_{i}=y_{i}^{*}, 0 \leq y_{i}^{*} \leq 1 \\
& y_{i}^{*}=0, y_{i}^{*} \leq 0
\end{aligned}
$$

among them, $\varepsilon_{i}$ is the random error term, $\varepsilon_{i} \sim N(0, \sigma 2), \beta$ is the regression parameter, $x_{i}$ is the independent variable, $y^{*}$ is the potential technical efficiency, and $y_{i}$ is the technical efficiency. Since the technical efficiency value measured by DEA is in the $0-1$ interval, the Tobit model with the left end point being 0 and the right end point being 1 is adopted.

The selection of independent variables is based on the above theoretical analysis and previous research $[3,13,16,40]$. There are three sets of independent variables in total. The first group is the characteristic variables of farmers. The variables of the basic characteristics of farmers mainly include the age of the head of the farmer, education level, and whether he is a cadre or not. According to the above theoretical analysis, there may be a negative correlation relationship between the age of the agricultural labor force and the technical efficiency of garlic production. According to the results of previous studies by scholars, there are two kinds of influences on farmers' age. The first type is that the older the householder is, the richer the planting experience is, and the long-term accumulation of planting experience is conducive to improving the efficiency of garlic planting production technology [20]; second, the older farmers are, the older their ideas are, the less educated they are on average, and the more unwilling or limited they are to accept advanced production technology, which will have a negative impact on improving the efficiency of production technology. The second group of independent variables describes the production characteristics of farmers, such as planting area, number of planting plots, and number of garlic planting varieties. According to the theory of return to scale, it can be divided into two situations. The first is that the scale of production does not reach the optimal scale, so as the scale of planting increases, the production efficiency will gradually increase within a certain range, and finally reach the optimal scale of planting. The second is that when the planting scale continues to expand and exceeds a certain critical point, that is, the optimal scale, the production efficiency will show a downward trend. In the actual survey, it is found that the larger the planting area of the farmers, the greater the capital invested by the farmers in agricultural production, which helps to improve the efficiency of production technology to a certain extent, but if the invested capital is not returned, it will increase accordingly. As for the large number of varieties of garlic planted, the input of farmers' production factors increases, and labor needs increase, but the selling prices of different kinds of garlic are different, which will appropriately increase garlic income. The third group of independent variables describes the characteristic variables of inputs, which mainly include other inputs such as land input, fertilizer input, pesticide input, mulching film input, labor input, irrigation cost, and so on. As the farmer's input variable, according to the theory of economies of scale, production efficiency will show an inverted U-shaped growth, that is, production efficiency will show an upward trend as the input increases, but if the input increases beyond a certain critical value, it will reduce production efficiency instead.

\subsection{Data}

The empirical data analysis of this article comes from the first-hand survey data collected by the author during 2020 who went for an interview and survey in 84 villages under 
the jurisdiction of Changcheng Town, Lanling Town, Moshan Town, and Shenshan Town in Lanling County, Linyi City, Shandong Province. The survey method adopts random sampling questionnaire survey and interviews with farmers. A total of 378 questionnaires were distributed, 18 invalid questionnaires were excluded, and a total of 360 valid questionnaires were collected. The effective rate of the questionnaires was $95.23 \%$. The questionnaire has five main parts: basic information of garlic growers' households, garlic growers' planting area and output, garlic growers' various inputs, garlic growers' annual income and other information, and influencing factors in garlic growers' production. The investigation effectively covers the relevant information needed for the analysis of the paper. The sampling method uses a combination of stratified sampling and random sampling. The survey form is household interview questionnaire survey. The data and indicators correspond to the time of 2020, which has strong academic research representativeness. The definition and descriptive statistics of each variable are shown in Table 2.

Table 2. Summary of descriptive statistics of the main variables.

\begin{tabular}{|c|c|c|c|}
\hline Variable Name & Meaning and Assignment & Mean & Standard Deviation \\
\hline \multicolumn{4}{|l|}{ Labor input index } \\
\hline Land input & Actual garlic planting area of farmers & 4.37 & 2.85 \\
\hline Material capital investment & $\begin{array}{l}\text { Garlic seed + Agricultural film + Fertilizer + } \\
\text { Pesticide + Labor Irrigation (CNY 10,000) }\end{array}$ & 1.46 & 1.13 \\
\hline Labor input & labor input (everyone a day) & 18.54 & 8.76 \\
\hline $\begin{array}{c}\text { Farmer output indicators } \\
\text { Total output value of garlic and garlic sprouts } \\
\text { Basic characteristics of farmers }\end{array}$ & Garlic and garlic sprout income (CNY 1000) & 2.95 & 2.21 \\
\hline Farmer's age & Calculated by actual age & 52.861 & 10.899 \\
\hline $\begin{array}{l}\text { Years of education of farmers } \\
\text { Basic family characteristics }\end{array}$ & actual years of education & 8.930 & 2.828 \\
\hline Number of people over 60 in the family & $\begin{array}{c}\text { actual number of people over } 60 \text { years old in the } \\
\text { household }\end{array}$ & 0.817 & 1.072 \\
\hline Farmers' health & Very $\operatorname{good}=5 \operatorname{good}=4$ normal $=3$ bad $=2$ worse $=1$ & 3.750 & 0.849 \\
\hline Village cadre & $1=$ yes, $0=$ no & 0.217 & 0.412 \\
\hline Family income & actual annual income & 1.188 & 1.416 \\
\hline \multicolumn{4}{|l|}{ Planting characteristics } \\
\hline Planting acres & actual number of acres of garlic planted & 4.373 & 2.855 \\
\hline Number of garlic varieties & actual number of garlic varieties grown & 1.206 & 0.491 \\
\hline $\begin{array}{l}\text { Number of plots } \\
\text { other }\end{array}$ & actual number of planted plots & 3.049 & 2.469 \\
\hline Amount of technical training & actual number of training sessions per year & 0.706 & 1.068 \\
\hline
\end{tabular}

Note: 1. The data are obtained by the members of the research team on the field survey in Lanling County, Shandong. 2. For the convenience of analysis, some variables have been classified and adjusted to the original data.

\section{Results and Discussion}

This paper firstly calculates the comprehensive technical efficiency (TE), the pure technical efficiency (PTE), and the scale efficiency (SE) of farmers in the first stage, and then uses the above three types of efficiency values of farmers to influence the efficiency of each environment. The variables are subjected to Tobit model regression analysis in the second stage, and finally, the inflection points of the above three types of efficiency values of farmers are analyzed in detail. The empirical estimation results are shown in Table 3.

Table 3. Estimation results of the impact of the aging of rural labor force on the production technology efficiency of the planting industry.

\begin{tabular}{cccc}
\hline Item & $\begin{array}{c}\text { (Model I) Explained } \\
\text { Variable: TE }\end{array}$ & $\begin{array}{c}\text { (Model II) Explained } \\
\text { Variable: PTE }\end{array}$ & $\begin{array}{c}\text { (Model III) Explained } \\
\text { Variable: SE }\end{array}$ \\
\hline Farmer's age & $(0.28) 0.0003$ & $(-0.07)-0.0001$ & $(0.37) 0.0004$ \\
Years of education of farmers & $(-0.85)-0.0034$ & $(-1.56)-0.0082$ & $(0.38) 0.0015$ \\
Number of garlic varieties & $(-1.18)-0.0282$ & $(-1.86)-0.0575^{*}$ & $(0.13) 0.0029$ \\
Amount of technical training & $(0.32) 0.0035$ & $(-0.88)-0.0122$ & $(0.77) 0.0078$ \\
\hline
\end{tabular}


Table 3. Cont.

\begin{tabular}{cccc}
\hline Item & $\begin{array}{c}\text { (Model I) Explained } \\
\text { Variable: TE }\end{array}$ & $\begin{array}{c}\text { (Model II) Explained } \\
\text { Variable: PTE }\end{array}$ & $\begin{array}{c}\text { (Model III) Explained } \\
\text { Variable: SE }\end{array}$ \\
\hline $\begin{array}{c}\text { Farmers' health } \\
\text { Number of plots }\end{array}$ & $(0.35) 0.0047$ & $(-1.11)-0.0193$ & $(1.20) 0.0152$ \\
Number of people over 60 in & $(-1.16)-0.0065$ & $(1.26) 0.0094$ & $(-3.81)-0.0203 * * *$ \\
the family & $(-2.29)-0.0261^{* *}$ & $(-2.60)-0.0384^{* *}$ & $(-0.48)-0.0052$ \\
Planting acres & $(-4.95)-0.0368^{* * *}$ & $(-7.13)-0.0691^{* * *}$ & $(0.53) 0.0039$ \\
Village cadre & $(0.02) 0.0004$ & $(0.51) 0.0185$ & $(0.28) 0.0075$ \\
$\begin{array}{c}\text { Family income } \\
\text { Likelihood/Chi-square test } \\
\text { statistic }\end{array}$ & $(7.45) 0.0678^{* * *}$ & $(4.61) 0.0550^{* * *}$ & $(7.26) 0.0659 * *$ \\
\hline
\end{tabular}

Note: 1 . The $T$ value in the parentheses in the table. $2 .^{*}, * *, * * *$ indicate that the statistical value is significant at the statistical level of $10 \%, 5 \%$, and $1 \%$, respectively. 3 . The data are obtained by the members of the research team conducting field investigations in Lanling County, Shandong.

(1) The impact of "farmer's age" on the efficiency of planting production technology.

The results of Model I and Model III show that the regression coefficients of "farmer age" are 0.0003 and 0.0004 , respectively, and have a significant positive impact on the comprehensive technical efficiency and scale efficiency (SE). From the results of Model II, it can be seen that the regression coefficient value of "farmer age" is -0.0001 , and it has a significant negative impact on pure technical efficiency (PTE). This means that although the age of the farmer has a negative effect on the pure technical efficiency of farmers, the negative effect does not exceed the positive effect on the scale efficiency, and thus has a significant positive effect on the comprehensive technical efficiency.

(2) The influence of family characteristic variables.

1) "Annual household income" has a significant positive impact on comprehensive technical efficiency, pure technical efficiency, and scale efficiency. The reason for this may be that if the annual household income is high, more funds are invested in planting, and auxiliary agricultural machinery can be purchased to help farmers with planting production and improve planting efficiency.

2) "The number of laborers aged 60 and over in the household labor force" has a significant negative impact on pure technical efficiency and comprehensive technical efficiency. This shows that the positive effects of the aging labor force in terms of experience, skills, and agricultural production specificity cannot resist the negative effects of the decline in physical strength and lack of energy caused by the aging labor force. The labor force over 60 years old has a low understanding and acceptance of new technology and knowledge, and the learning ability is limited; the greater the labor force, the lower the technical efficiency. The aging labor force is weak in anti-risk ability, strong in conservative consciousness, relatively insufficient in energy, and unwilling to expand the scale of operations, thus unable to obtain scale returns, so it has a negative impact on scale efficiency.

(3) The influence of garlic planting characteristic variables.

1) The "number of plots" has a significant negative impact on scale efficiency. This shows that the degree of arable land fragmentation has a certain negative impact on farmers' arable land input behavior and then affects farmers' output benefit expectations and is not conducive to the improvement of farmers' agricultural production technical efficiency.

2) This is also the same as the research results of scholars Tian Hongyu et al. (2019) [9].

3) "Number of garlic varieties" has a positive effect on scale efficiency. Inconsistent with the previous assumptions, the more varieties of garlic planted, the larger 
the planting scale will be. According to the theory of economies of scale, the planting scale efficiency increases. Different kinds of garlic have different maturity periods. Planting a variety of garlic according to different maturity periods can increase the output value of garlic in the same planting time. Therefore, the more garlic varieties, the higher the scale efficiency.

4) The number of acres of garlic planted has a negative impact on the comprehensive technical efficiency and pure technical efficiency. Under the established technical efficiency, the higher the number of acres planted, the lower the technical efficiency. Because garlic planting is still artificially planted now, under the existing technology, the more acres of garlic planting area, the higher the labor input, the lower the technical efficiency.

(4) Further analysis of the inflection point of each efficiency score.

According to the calculation of the comprehensive technical efficiency (TE), the pure technical efficiency (PTE), and the scale efficiency (SE) of the farmers, the age of the sample growers according to the new age group proposed by the United Nations World Health Organization is divided into four categories: 18 to 44 years old as young people, 45 to 59 years old for middle-aged people, 60 to 74 years old for the young to the old people, and 75 to 89 years old for elderly people. The specific distribution of efficiency scores is shown in Figure 3. The selected sample farmers account for $26.67 \%$ of the elderly over 60 years old in total, which far exceeds the aging standard established by the internationally accepted standards, and the degree of aging is serious.

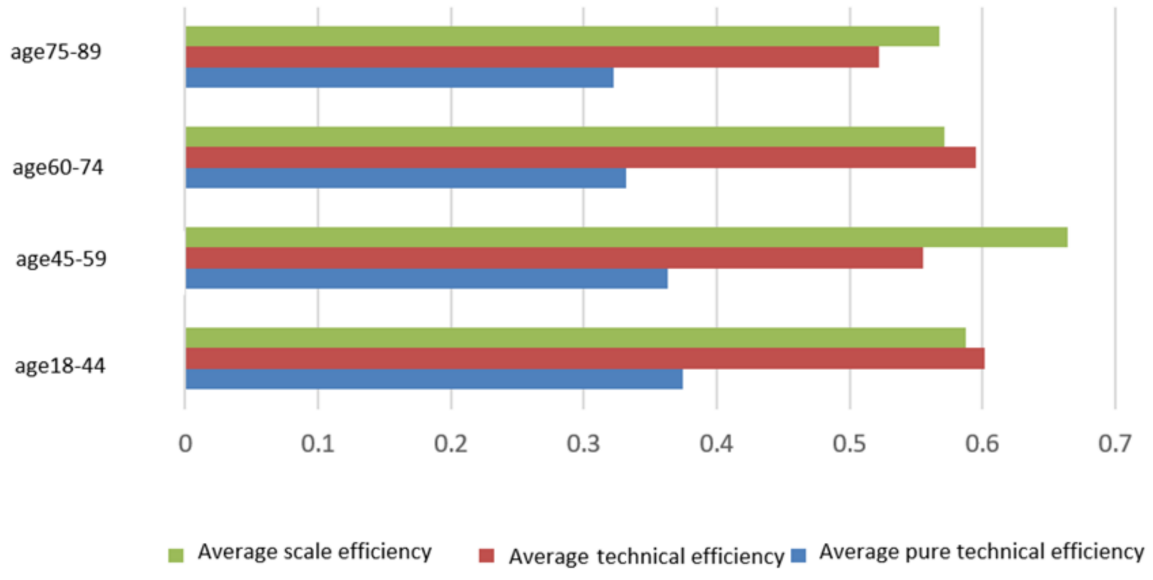

Figure 3. The relationship between the age of the rural labor force and the efficiency of planting production technology.

It is not difficult to see from Figure 3 that as the average age of the agricultural labor force continues to increase, the level of production technology efficiency on the farmer household level continues to decline. The comprehensive technical efficiency and pure technical efficiency reached the peak at the age of 18 to 44 , while the scale efficiency reached the highest value of scale efficiency between the ages of 45 and 59, and thereafter also showed a trend of gradual decline.

Table 3 is the estimated result of the relationship between the age of garlic growers and the efficiency of garlic production technology. The negative coefficient of the independent variable illustrates the positive impact on technical efficiency, and vice versa. The DEA results show that the age of garlic growers is negatively correlated with the efficiency of production technology. Therefore, it can be seen that the aging of the agricultural labor force may actually have a negative impact on the technical efficiency of garlic production. Since most of the interviewees have little difference in the age of farmers, the difference in labor is little, so the impact on garlic production efficiency is not obvious, but it also reflects the serious aging of the agricultural labor force. As shown in Table 3, the estimated 
coefficient of the number of laborers in the rural households over 60 years old is significantly negatively correlated. Studies have shown that a labor force 60 years old and above has low understanding and acceptance ability of new technologies and knowledge, and their learning ability is limited. At the same time, aging reduces the physical fitness of the labor force, and its health will be appropriately affected. Garlic production and planting require physical strength, and if the health of the labor force is reduced and physical fitness is reduced, they all result in a decrease in the efficiency of garlic planting scale. In the actual survey, it is found that $26.67 \%$ of the rural households are still over 60 years old and engaged in farming. The family aging ratio refers to the ratio of the family's elderly labor force over 60 years old to the family's labor force. The higher the family aging ratio, the lower the more comprehensive efficiency. In other words, the actual impact of the aging of garlic growers on the efficiency of garlic production is obviously negative.

The results here provide empirical evidence for the theoretical analysis in Section 2 but are inconsistent with some previous studies [41,42]. Different from the previous ones, previous research mainly focused on the production of field crops, which are easy to be used by agricultural machinery. This research focuses on garlic, a labor-intensive economic crop that is mostly artificially grown. In previous studies, it can be found that the negative impact of the aging of the agricultural labor force on the production of food crops in the field can be partially or even completely alleviated through the use of agricultural machinery. For example, some previous studies believed that with the increasing aging of the agricultural labor force, elderly farmers would use more agricultural machinery in rice production, thereby reducing the loss of technical efficiency [38]. In contrast, garlic is a labor-intensive economic crop. In addition to the huge demand for artificial cultivation, it is also difficult to use agricultural machinery in garlic production, especially in Shandong Province, which has a large population but less land per capita. In fact, the small distance between garlic planting land is not conducive to the entry of agricultural machinery into the field, and agricultural machinery cannot be widely used in garlic production. With the increase in garlic growers age, the artificial input in garlic production will be insufficient, and the insufficient utilization of agricultural machinery plays a vital role. In this case, the increasing aging of garlic growers will inevitably have a negative impact on the technical efficiency of garlic production. In terms of other factors, the results show that the amount of technical training, the number of years of farmers' education, and the health of farmers are also significantly related to the technical efficiency of garlic production. As shown in Table 3, there is a negative correlation between the number of years of education of garlic growers and technical efficiency. As several previous studies have analyzed, the low level of education of garlic growers directly affects important factors of agricultural development, and then it will directly affect agricultural production yields [11]. We also found that the participation of garlic growers in technical training is negatively related to the comprehensive technical efficiency. In view of the fact that most agricultural extension activities are organized in village committees, in this study, farmers can learn the most advanced planting techniques and methods by participating in technical training, and through the exchange and discussion with other farmers, learn from each other's planting experience is very beneficial for improving overall efficiency, thereby promoting the technical efficiency of garlic production. In addition, as in the previous study [43], the health of garlic growers is also negatively correlated with the overall technical efficiency. The productivity of the age group above 44 years old decreases linearly, and the productivity decreases due to the decline in physical strength and energy. Please note that, unlike the research conducted by scholars in the previous article [7], which showed that age has no significant effect on the utilization efficiency of cultivated land, Lanling County is the main garlic producing area in China. Different families in the same village have different acres of land. However, the degree of land fragmentation is too high. The results of this paper show that the high degree of land fragmentation will lead to a decrease in land use efficiency. Therefore, the results here also show that better 
garlic technical training and low-division land will help improve the technical efficiency of garlic production.

\section{Conclusions and Policy Implications}

Based on the survey data of farmers in Lanling County, Shandong Province, this paper uses the DEA-Tobit model to study the impact of the aging of the rural labor force on the technical efficiency scores of garlic growers and other environmental variables on the production technical efficiency of the planting industry. Furthermore, the paper analyzed the inflection point of the relationship between each efficiency score and the age of rural labor force. The results show the following:

(1) The high degree of aging of the agricultural labor force in Lanling County, Shandong, is mainly due to the rapid urbanization process and the rapid development of the economic level which leads to the transfer of young and middle-aged agricultural labor force to non-agricultural sectors. With the birth rate remaining unchanged, the problem of the aging of the agricultural labor force has become prominent.

(2) According to the efficiency value analysis obtained by the DEA model, it is found that the older the garlic grower is, the lower the production technology efficiency value; the different education levels will affect the garlic production efficiency value; the greater the garlic technology training times per year, the higher the production technology efficiency, but training more than three times will be negatively correlated with the efficiency of production technology; the technical efficiency of garlic production was affected by different health degrees; the higher the health level, the higher the production efficiency of garlic planting; the more varieties of garlic planted, the greater the negative effect on the technical efficiency of garlic production was observed.

(3) According to regression calculations, seven factors, such as education level, health level, number of planting plots, cadre or not, the number of garlic varieties, the amount of training, and the age of the respondents, have not shown a significant impact. The number of laborers over 60 in the household, the number of acres of garlic planting, and the annual income of the farmer households: These three factors have a significant impact. The number of years of education of farmers does not reflect its significant factor because the farmers' garlic planting mainly relies on empirical planting, which is not highly correlated with the level of education, and it is difficult to affect the technical efficiency of garlic planting. The higher the number of acres of garlic planted, and insufficient labor input will reduce the efficiency of garlic planting. The more laborers in the family over the age of 60 , the weaker the physical energy of laborers will be than that of young laborers. Therefore, the more efficient the technical efficiency of garlic planting for farmers is lower. The higher the annual family income of farmers, the higher the cost of garlic planting. They purchase agricultural machinery to assist garlic planting to promote the technical efficiency of garlic planting.

Based on the analysis, the aging of the agricultural labor force in Lanling County, Shandong, has a negative impact on agricultural production. The elderly labor force is experienced but physically weaker than the young labor force. According to actual surveys, it is found that the cultivation of the elderly labor force is driven by subjective willingness, but when the elderly labor force gradually withdraws after agricultural production, the problems that agricultural development and guaranteeing agricultural production need to face in the future have become important problems that need to be solved. Therefore, there are the following five policy implications: (1) The Chinese government should establish agricultural socialization service organization through intensive capital and technology so as to increase the intensive degree of garlic planting, promote garlic production and increase garlic planting production efficiency. (2) Township governments should create conditions for large-scale garlic operations, establish relevant platforms, and promote land transfer. (3) The Chinese government should continue to improve the rural old-age security system and cultivate new agricultural business entities. (4) Farmers should adjust the 
planting structure and protect characteristic industries. Enhance market competitiveness and flexibility in responding to market risks. (5) Scientific Research institutes should speed up the research on garlic agricultural machinery, promote the improvement of garlic agricultural mechanization, and increase the output and income of farmers.

Author Contributions: Conceptualization, F.S.; methodology, F.S. and Y.Y.; investigation, F.S. and S.Z.; writing —original draft preparation, F.S.; writing—review and editing, F.S., Y.Y. and S.Z.; visualization, F.S.; supervision, F.S.; funding acquisition, Y.Y. and F.S. All authors have read and agreed to the published version of the manuscript.

Funding: This work is supported in part by National Natural Science Foundation of China under grant No. 71071069 and Science and Technology Development Project of Jilin Province under grant No. 20210402033GH.

Institutional Review Board Statement: Not applicable.

Informed Consent Statement: Informed consent was obtained from all subjects involved in the study.

Data Availability Statement: Data is available at http:/ / www.lanling.gov.cn/ (accessed on 9 May 2021).

Conflicts of Interest: The authors declare no conflict of interest.

\section{References}

1. The World Bank. Available online: https://data.worldbank.org/indicator/SP.POP.65UP.TO.ZS?end=2019\&locations=CN\&start= 1985\&view=chart (accessed on 9 May 2021).

2. National Bureau of Statistics of China. Available online: http://www.stats.gov.cn/tjsj/ndsj/2020/indexch.htm (accessed on 9 May 2021).

3. Li, M.; Sicular, T. Aging of the labor force and technical efficiency in crop production. China Agric. Econ. Rev. 2013, 5, 342-359. [CrossRef]

4. Li, L.; Li, Y. Analysis and reflect on the problem about ageing labor engaged in agricultural production: Based on the second national agricultural census statistics in China. Issues Agric. Econ. 2009, 6, 61-66.

5. Hu, X.; Zhong, F. Impact of the aging of rural population on grain production: An analysis based on fixed observation point data in rural areas. Chin. Rural. Econ. 2012, 7, 29-39.

6. $\mathrm{Hu}, \mathrm{X}$.; Zhong, F. The impact of population aging on crop production: Based on the analysis of wheat and cotton crops. Issues Agric. Econ. 2013, 2, 36-43.

7. Lin, B.; Deng, H. An empirical analysis on the impact of the aging of agricultural labor force on farmland use efficiency: Based on the fixed observation point data in rural Zhejiang province. Chin. Rural. Econ. 2012, 4, 15-25.

8. Thiede, B.C.; Brown, D.L.; Sanders, S.R.; Glasgow, N.; Kulcsar, L.J. A Demographic Deficit? Local Population Aging and Access to Services in Rural America, 1990-2010. Rural. Sociol. 2017, 82, 44-74. [CrossRef] [PubMed]

9. Smailes, P.; Griffin, T.; Argent, N. Demographic Change, Differential Ageing, and Public Policy in Rural and Regional Australia: A Three-State Case Study. Geogr. Res. 2014, 52, 229-249. [CrossRef]

10. Toossi, M.A. Century of Change: A century of change: The U.S. labor force, 1950-2050. Mon. Labor Rev. 2002, 125, 15-28.

11. Despotovic, A.; Joksimovic, M.; Jovanovic, M. Impact of demographic changes on agricultural development in Montenegro. Ekon. Poljopr. Econ. Agric. 2015, 62, 613-625. [CrossRef]

12. Lindh, T.; Malmberg, B. Age structure effects and growth in the OECD, 1950-1990. J. Popul. Econ. 1999, 12, 431-449. [CrossRef]

13. Guo, X.; Zuo, Z. Analysis on rural households' selection of production technology and technical efficiency in the traditional agricultural areas. Agrotech. Econ. 2015, 1, 42-53.

14. Liu, C.; Wang, J.; Chen, Q.; Zhu, M. Research on the Measurement of China's Corn Production Technical Efficiency and Its Influencing Factors-Based on the Empirical Study of Provincial Panel Data from 1995 to 2015. World Agric. 2018, 8, 139-145.

15. Saiyut, P.; Bunyasiri, I.; Sirisupluxana, P.; Mahathanaseth, I. The impact of age structure on technical efficiency in Thai agriculture. Kasetsart J. Soc. Sci. 2019, 40, 539-545. [CrossRef]

16. Awudu, A.; Richard, E. Technical efficiency during economic reform in Nicaragua: Evidence from farm household survey data. Econ. Syst. 2001, 25, 113-125.

17. Qiao, Z.; Huo, X.; Zhang, B. The impact of agricultural labor aging on productivity of labor-intensive agricultural products: An empirical analysis based on 745 apple farmer households of Shaanxi and Gansu province. Econ. Surv. 2018, 35, 73-79.

18. Fried, H.O.; Tauer, L.W. The Aging, U.S. Farmer: Should We Worry. In Advances in Efficiency and Productivity; Springer: Cham, Switzerland, 2016; pp. 391-407.

19. Bashir, M.K.; Ali, A. Estimation of economic and production efficiency of potato production in central Punjab, Pakistan. Custos E Agronegocio Line 2021, 17, 2-23.

20. Hakim, R.; Haryanto, T. Technical efficiency among agricultural households and determinants of food security in East Java, Indonesia. Sci. Rep. 2021, 11, 1-9. [CrossRef] 
21. Anser, M.K.; Ali, M.; Anwar, F.; Usman, M. Subjective age and job satisfaction: A moderated mediation model of job burnout and chronological age. Front. Public Health 2020, 8, 62. [CrossRef]

22. Monchuk, D.C.; Chen, Z.; Bonaparte, Y. Explaining production inefficiency in China's agriculture using data envelopment analysis and semi-parametric bootstrapping. China Econ. Rev. 2010, 21, 346-354. [CrossRef]

23. Ray, K.; Hasan, S.S.; Goswami, R. Techno-economic and environmental assessment of different rice-based cropping systems in an inceptisol of West Bengal, India. J. Clean Prod. 2018, 205, 350-363. [CrossRef]

24. Pan, X.; Liu, Q.; Peng, X. Spatial club convergence of regional energy efficiency in China. Ecol. Indic. 2015, 51, 25-30. [CrossRef]

25. Aslam, M.S.; Xue, P.H.; Aslam, M.S.; Xue, P.H. Assessment of rice and wheat production efficiency based on data envelopment analysis. Environ. Sci. Pollut. Res. 2021, 28, 38522-38534. [CrossRef] [PubMed]

26. Sun, Z.L.; Li, X.D. Technical Efficiency of Chemical Fertilizer Use and Its Influencing Factors in China's Rice Production. Sustainability 2021, 13, 1155. [CrossRef]

27. Sapkota, M.; Joshi, N.P. Factors Associated with the Technical Efficiency of Maize Seed Production in the Mid-Hills of Nepal: Empirical Analysis. Int. J. Agron. 2021, 2021, 1-8. [CrossRef]

28. Mezgebo, G.K.; Mekonen, D.G.; Gebrezgiabher, K.T. Do smallholder farmers ensure resource use efficiency in developing countries? Technical efficiency of sesame production in Western Tigrai, Ethiopia. Heliyon 2021, 7, e07315. [CrossRef]

29. Angon, E.; Bragulat, T. Key factors affecting the technical efficiency of bee farms in the province of La Pampa (Argentina): A two-stage DEA approach. Revista De La Facultad De Ciencias Agrararias 2021, 53, 150-163. [CrossRef]

30. Ma, J.; Zeng, Y.; Wu, B. Labor endowments and production and management decisions of rural households in poverty-stricken areas. China Popul. Resour. Environ. 2013, 5, 135-142.

31. Huang, J.; Rozelle, S. Technological change: Rediscovering the engine of productivity growth in China's rural economy. J. Dev. Econ. 1996, 49, 337-369. [CrossRef]

32. Tian, W.; Wan, G. Technical efficiency and its determinants in China's grain production. J. Prod. Anal. 2000, 13, 159-174. [CrossRef]

33. Chavas, J.P.; Petrie, R.; Roth, M. Farm household production efficiency: Evidence from the Gambia. Am. J. Agric. Econ. 2005, 87, 160-179. [CrossRef]

34. Mwalupaso, G.E.; Wang, S.; Rahman, S.; Alavo, E.J.P.; Tian, X. Agricultural information and technical efficiency in maize production in Zambia. Sustainability 2019, 11, 2451. [CrossRef]

35. Yan, J.; Chen, C.; Hu, B. Farm size and production efficiency in Chinese agriculture: Output and profit. China Agric. Econ. Rev. 2019, 11, 20-38. [CrossRef]

36. Zhang, Z. Age difference in labor productivity and Lewis turning point. China Rural. Econ. 2011, 08, 12-21.

37. Tian, H.; Feng, X. Land fragmentation and rice production technology efficiency. J. S. China Agric. Univ. 2019, $04,68-79$.

38. Alvarez, A.; Arias, C. Technical efficiency and farm size: A conditional analysis. Agric. Econ. 2004, 30, 241-250. [CrossRef]

39. Chen, F.; Zhang, C.; Luo, Y.; Qiu, H. Impact of farmers' planting experience on technical efficiency: Micro evidence from maize-producing households in four provinces in China. J. Agrotech. Econ. 2015, 5, 12-21.

40. Seymour, G. Women's empowerment in agriculture: Implications for technical efficiency in rural Bangladesh. Agric. Econ. 2017, 48, 513-522. [CrossRef]

41. Zhou, H.; Wang, Q.; Zhang, Q. Research on ageing of rural labour force and efficiency loss of rice production: Based on the perspectives of social service. Chin. Popul. Sci. 2014, 3, 53-65.

42. Peng, D.; Wen, L. Does the aging and feminization of rural labor force reduce grain production efficiency? A comparative analysis between the North and South China based on the stochastic frontier method. Agrotech. Econ. 2016, 2, 32-44.

43. Yang, Z.; Maierdan, T.; Wang, Y. Impact of the aging of rural labor force on agricultural technical efficiency: The empirical study based on the CHARLS2011. Soft Sci. 2014, 28, 130-134. 